\title{
COMPRESSION RESISTANCE OF SMALL PAPERBOARD PACKAGING SHAPES
}

\author{
Josip Bota (D), Sonja Jamnicki Hanzer (D), Dubravko Banić (D), Maja Brozović \\ University of Zagreb, Faculty of Graphic Arts, Zagreb, Croatia
}

\begin{abstract}
Rectangles are the most common packaging shapes. Their stability under compression can vary according to different types of paperboard as well as panels ratios. Rectangular shapes have advantages in transportation and production but are not the only shapes that paperboard packaging has to offer. This paper investigates seven packaging shapes with different cross-sections while keeping the same height and amount of material used. The tested shapes were made with two types of paperboard (with recycled fibre and virgin pulp) and different grammage. The testing was conducted using a modified Crush Test (Lorentzen \& Wettre Crush Tester). The results showed that cylinder shape has the most compression resistance while triangular prism and rectangular prism (1:4 panel ratio) the least. Testing rectangles with different panel ratios together with the results of other shapes led to the conclusion that compression resistance mainly depends on the size of the panel. If a shape has larger (less number of) panels it has less resistance to vertical pressure (stackability).
\end{abstract}

Key words: paperboard packaging, packaging shapes, compression resistance, stackability

\section{INTRODUCTION}

Primary and secondary packaging play two important roles: product safety and communication with the consumer. Packaging can have additional benefits and setbacks but this paper is focused on the technological aspect of shape. Shape of the packaging is usually determined according to multiple factors: budget - cost of material, production and transportation, brand - recognizable and unique shape, product requirements - products conditions needed to avoid spoilage or damage.

The other aspect of shape is the communicational role. Packaging can have multiple effects on customers. The experiment from Becker et al., (2011) showed that angular packaging shape may inspire intense taste sensations and that designers should create the package according to taste of the food product. According to Pantin-Sohier, (2009) shapes have an effect on the brand image, but this is mostly focused on plastic packaging and packaging materials that are more versatile and moldable. Shapes and size can attract or alienate a consumer (Al-Turaif, 2009) and can also have a big impact when consumers are subjected to time pressure decision making (Silayoi et al, 2004), even different panel ratios of rectangular packaging can influence the purchasing decision (Raghubir et al, 2006).

On the other hand, unique packaging shapes can raise the production and transport cost. Transport packages made from corrugated cardboard are mostly rectangular shape. Accordingly most of the primary and secondary packaging are rectangular as well in order to easily and tightly fit the transport boxes to ensure safety of the product and the packaging. Unique shapes usually need additional inserts or cushioning materials to avoid damage of the packaging during transport. Also, paper and paperboards are recyclable materials (Kirwan, 2011) and there are defined in paperboard grades (DIN Standard 19303 "Paperboard - Terms and grades") according to different levels of recycled/secondary fibre, type of pulp, coatings and color. This has an impact on mechanical properties of paperboard. Recycling can decrease density, tensile and bursting strength, but can increase tear strength (Wistara et al, 1999). Mechanical properties of paperboard like other materials have a cumulative effect when applied to shapes (Vable, 2012). So the same sheets of material will have various results according to shape.

Instruments exist for testing compression and stacking resistance of transport packages and which are in adherence to ISO 12048 Packaging - "Compression and stacking tests" but they are not adequate for testing low forces and small packaging shapes. There are no instruments or standards for testing compression resistance of small paperboard packaging. Crush test instruments (Ring and Edge Crush test, ISO 12192:2011 and ISO 3037:2013 respectively) are used to characterize the compression resistance of elements for corrugated paperboard. They have a smaller testing format and can record weaker forces thus appropriate to obtain the needed results.

The goal of this paper is to investigate what prism shape has the best/worst compression resistance and compare it within different paperboard grades and grammages. 


\section{METHODS}

\subsection{Materials}

The paperboards chosen are commonly used for packaging of food, drugs and other products. Paperboard specifications, grades (according to DIN Standard 19303 "Paperboard - Terms and grades") and nomenclature are seen in Table 1. The paperboard was conditioned according to the ISO 187:1990 standard at temperature of $23^{\circ} \mathrm{C} \pm 1^{\circ} \mathrm{C}$ and humidity RV $50 \% \pm 2 \%$ before and during the testing.

Table 1: Paperboard samples nomenclature and specifications

\begin{tabular}{|c|c|l|l|l|}
\hline sample name & grammage & \multicolumn{1}{|c|}{ grade } & thickness & manufacturer \\
\hline GD230 & $230 \mathrm{~g} / \mathrm{m}^{2}$ & GD2(recycled/secondary fibre) & $0,29 \mathrm{~mm}$ & Umka color $^{\circledR}$ \\
\hline GD280 & $280 \mathrm{~g} / \mathrm{m}^{2}$ & GD2(recycled/secondary fibre) & $0,36 \mathrm{~mm}$ & Umka color $^{\circledR}$ \\
\hline GD350 & $350 \mathrm{~g} / \mathrm{m}^{2}$ & GD2 (recycled/secondary fibre) & $0,45 \mathrm{~mm}$ & Umka color $^{\circledR}$ \\
\hline GC250 & $250 \mathrm{~g} / \mathrm{m}^{2}$ & GC1 (virgin mechanical pulp) & $0,41 \mathrm{~mm}$ & Ningbo $^{\circledR}$ \\
\hline GC270 & $270 \mathrm{~g} / \mathrm{m}^{2}$ & GC2(virgin mechanical pulp) & $0,46 \mathrm{~mm}$ & AllyKing $^{\circledR}$ \\
\hline
\end{tabular}

\subsection{Samples}

To test the compression resistance of shapes, just the bases were used, in order to isolate the influence of the closing, locking and other flaps commonly found in packaging layouts. Test samples were prepared by using the same amount of material. Each sample had the same surface area ( $250 \mathrm{~mm} \times 50 \mathrm{~mm})$ but differed in the positions of creasing lines to achieve seven types of shapes. The fibre orientation is vertical in order to ensure the highest degree of compression resistance, and how it is commonly oriented in packaging production. The shapes and their specifications are seen in Table 2 . The glue area is the same on each shape and is glued by using a water based dispersion of polyvinyl acetate with additives (Signokol ${ }^{\circledR}$ ) which is commonly used in the packaging line.

Table 2: Paperboard samples nomenclature and specifications

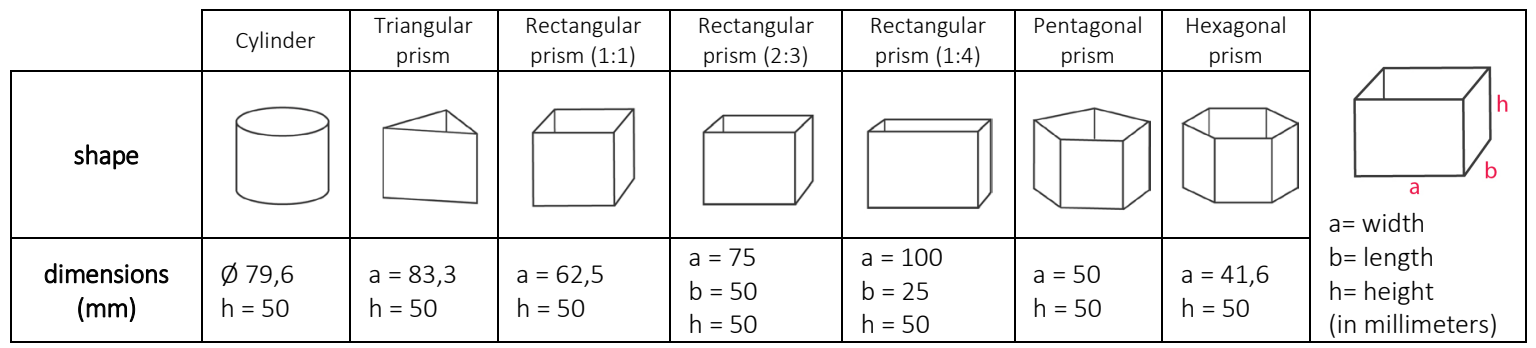

\subsection{Measurement procedure}

After the glue was completely dry (24h after gluing) the samples were tested with vertical pressure using a modified Crush test instrument (Lorentzen \& Wettre Crush Tester). The samples were pressed between two plates so the force was applied on the upper and lower edges of the shapes. The test speed (movement of the upper plate) was $48,0 \mathrm{~mm} / \mathrm{min}$. The instrument records the maximum force that the samples withstand till barreling occurs (shape deformation). Each shape and material was tested with ten identical samples.

\subsection{Calculations}

In order to compare different shapes and types of paperboard and to omit the influence of grammage a compression index was calculated. The formula was devised resembling the bursting index from the ISO 2759-2001 standard.

$I=\frac{F}{g}\left(N \cdot g / m^{2}\right)$

I - Compression index $\left(\mathrm{N} \cdot \mathrm{m}^{2} / \mathrm{g}\right) ; \mathrm{F}$ - Force of vertical pressure $(\mathrm{N}) ; \mathbf{g}$ - Grammage of paperboard $\left(\mathrm{g} / \mathrm{m}^{2}\right)$ 


\section{RESULTS AND DISSCUSION}

The results in Figure 1 show compression resistance force for seven investigated shapes each made from five different paperboards. According to the results cylinder shape showed the highest compression resistance by far. This confirmed previous research that cylinders and cones have better dynamic strength than rectangular ones (Hoffmann, 2000). Collectively it is visible that the GC270 sample showed the best results in all shapes except with the cylinder shape, the best result there was GD350. In the cylinder shape of the GD350 sample we can assume that maybe the larger grammage gives additional support in relation to other shapes. This is an interesting finding and should be additionally explored. GD270 is made from virgin mechanical pulp and was expected to overperform paperboards with recycled fibre but it wasn't clear at what grammage would GD paperboards show same characteristics as GC. The least compression resistance for GD230 and GD280 was with triangular prism shape but for the GD350, GC250 and GC270 it was with the rectangular prism (1:4) shape. The smaller panels of the rectangular prism $(1: 4)$ in the weaker material could act as a type of support for the object. From the results it is also visible that the GD350 paperboard with recycled/secondary fibre could replace GD250 for all types of shapes.
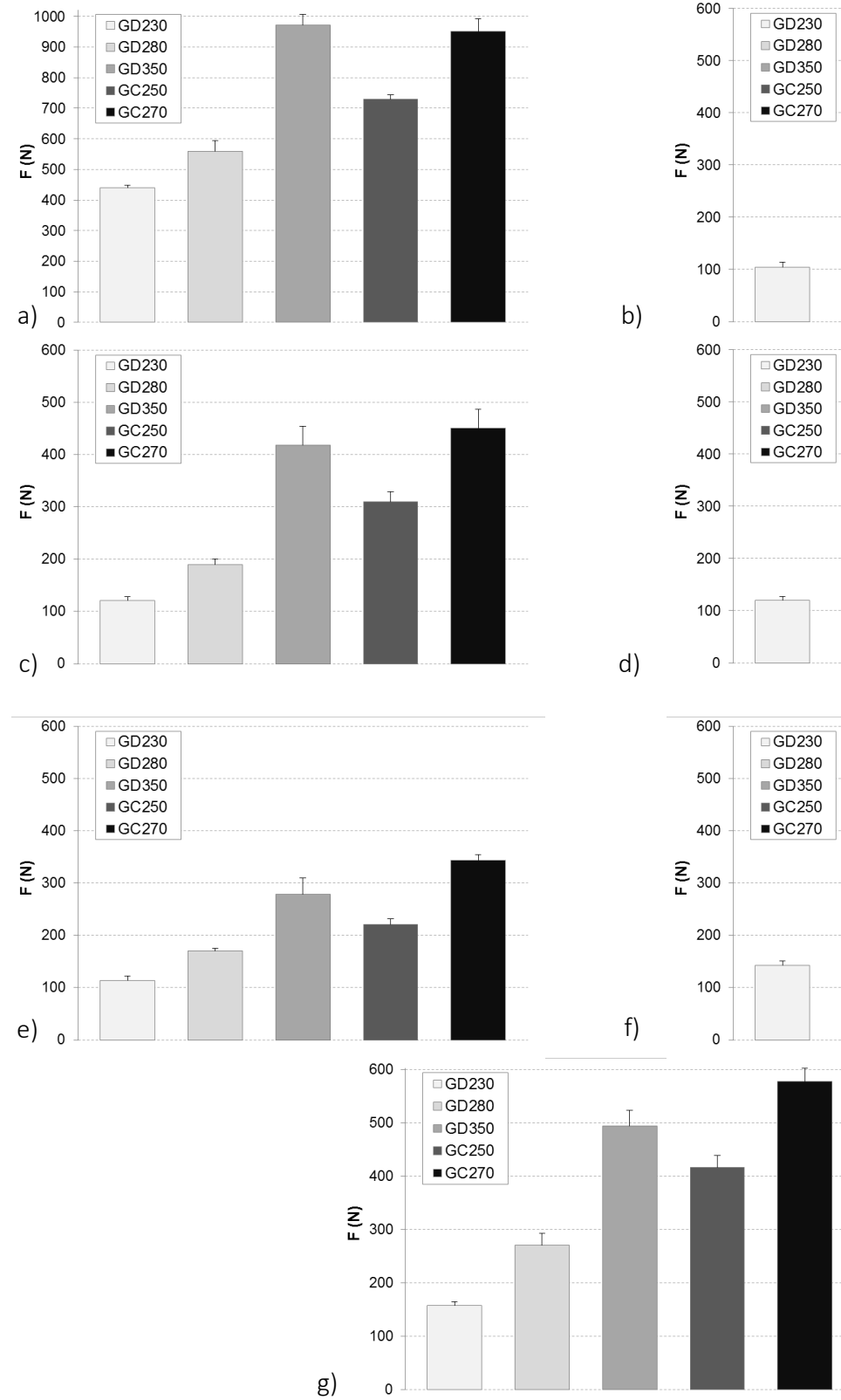

b)

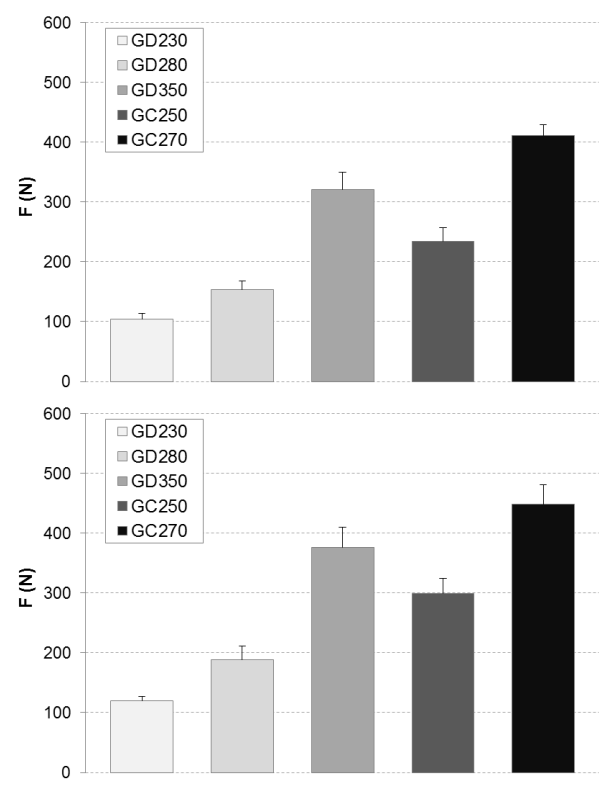

d)

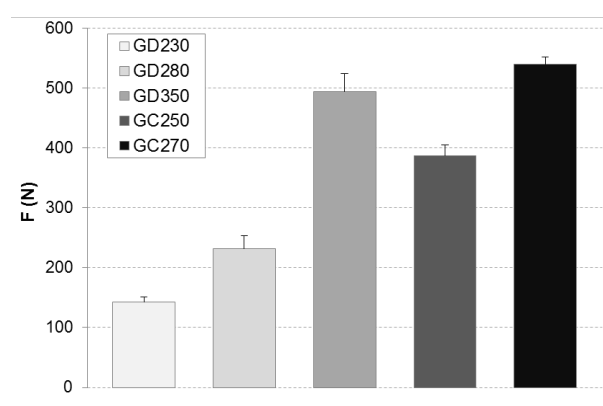

Figure 1: a) Cylinder; b) Triangular prism; c) Rectangular prism (1:1); d) Rectangular prism (2:3); e) Rectangular prism (1:4); f) Pentagonal prism; g) Hexagonal prism 
In order to compare the performance of paperboards according to shape, the cylinder shape values (as the highest in all samples) were set as a benchmark. This calculation is presented in Table 3. The shapes are listed from the highest values to the lowest except in the case of triangular prism for the GD230 and GD280. Cylinder shape can't be easily compared to other shapes because it doesn't have any creasing or folding (no sharp edges), so no visible panels. It can be viewed as a shape with endless amount of panels. All samples were made from the same amount of material so if the shape has more panels the panels are smaller in size. It can be seen that the smaller the panel the higher the compression resistance. Large panels, as a weak point can be best observed in the case of rectangular shapes with different panel rations.

Also, the results show that when the grammage of GD2 paperboard is larger, the lesser the difference between the cylinder and other shapes. The same case can be observed with the GC grade paperboards. This can be credited to the material thickness and other mechanical properties of the paperboards that change with the increase of thickness and weight.

Table 3: Compression values in relation to the cylinder shape

\begin{tabular}{|r|c|c|c|c|c|}
\cline { 2 - 6 } \multicolumn{1}{c|}{} & GD230 & GD280 & GD350 & GC250 & GC270 \\
\hline Cylinder & \multicolumn{5}{|c|}{$100,0 \%$} \\
\hline Hexagonal prism & $35,7 \%$ & $48,4 \%$ & $50,9 \%$ & $57,1 \%$ & $60,8 \%$ \\
\hline Pentagonal prism & $32,5 \%$ & $41,4 \%$ & $50,8 \%$ & $53,1 \%$ & $56,9 \%$ \\
\hline Rectangular prism (1:1) & $27,4 \%$ & $33,9 \%$ & $43,0 \%$ & $42,6 \%$ & $47,5 \%$ \\
\hline Rectangular prism (2:3) & $27,2 \%$ & $33,7 \%$ & $38,7 \%$ & $41,0 \%$ & $47,2 \%$ \\
\hline Triangular prism & $23,8 \%$ & $27,4 \%$ & $28,6 \%$ & $32,1 \%$ & $43,3 \%$ \\
\hline Rectangular prism (1:4) & $25,9 \%$ & $30,4 \%$ & $33,0 \%$ & $30,3 \%$ & $36,1 \%$ \\
\hline
\end{tabular}

But to fully compare the values with excluding the grammage of paperboard a Compression index was calculated according to formula in Section 2.4. The results of compression indexes are displayed in Table 4. The compression index shows the neutral specification of material and how does each material perform according to shape. GC270 paperboard shows, by far, the highest values across all shapes and paperboards. According to these results it can be said that the GD350 is equivalent to the GD250 sample. From these results it can also be seen the larger the grammage the better the index. The biggest difference is seen between GD280 and GD350.

Table 4: Compression index of paperboard samples in comparison with shape

\begin{tabular}{|r|r|r|r|r|r|}
\cline { 2 - 6 } \multicolumn{1}{c|}{} & \multicolumn{5}{c|}{ Compression index (N·m2/g) } \\
\cline { 2 - 6 } & GD230 & GD280 & GD350 & GC250 & GC270 \\
\hline Cylinder & 1,914 & 1,999 & 2,778 & 2,918 & 3,519 \\
\hline Hexagonal prism & 0,683 & 0,968 & 1,414 & 1,667 & 2,140 \\
\hline Pentagonal prism & 0,623 & 0,827 & 1,411 & 1,549 & 2,001 \\
\hline Rectangular prism (1:1) & 0,525 & 0,677 & 1,196 & 1,242 & 1,673 \\
\hline Rectangular prism (2:3) & 0,520 & 0,674 & 1,074 & 1,198 & 1,660 \\
\hline Triangular prism & 0,456 & 0,549 & 0,917 & 0,938 & 1,524 \\
\hline Rectangular prism (1:4) & 0,495 & 0,608 & 0,795 & 0,884 & 1,272 \\
\hline
\end{tabular}

It is important to note the there is a difference in volume of the shapes. Cylindrical prism has the biggest volume followed by hexagonal prism and the volume further drops when the shape has fewer numbers of panels. When grouping the tested shapes it is important to note that some shapes like pentagonal and cylinder prism cause a waste of space when packed for shipping, and that type of packaging would require additional fillers. According to previous research and mathematical papers it is theorized and proven that hexagonal shapes are an optimal structure and the best material-volume ratio(Hales, 1999; Räz, 2016). This theory is applied in furniture construction and proven to be best in impact behavior, energy absorption and compression (Guo et al., 2010; Wang et al., 2009; Wang, 2009) which is also used in filling constructions for 3D printing (Lu et al., 2018). 


\section{CONCLUSIONS}

This research was aimed to investigate the difference between small packaging shapes together with the use of different types of paperboards. For this research a new type of testing was developed using Crush test instrument. The results led to these conclusions:

- Cylinder shape proved to be the best option for vertical compression resistance when using the same amount of material, followed by hexagonal prism, pentagonal prism, rectangular prism (1:1), rectangular prism (2:3), triangular prism and rectangular prism (1:4)

- $\quad$ The weak points of angular prisms are large panels. They decrease the compression resistance if compared with smaller panels.

- $\quad$ The gap of compression resistance values between different shapes is smaller when using larger grammage.

- Paperboards with recycled/secondary fibres display weaker mechanical properties for compression resistance when compared with paperboards made from virgin mechanical pulp.

- $\quad 350 \mathrm{~g} / \mathrm{m}^{2} \mathrm{GD} 2$ can substitute $250 \mathrm{~g} / \mathrm{m}^{2} \mathrm{GC1}$ paperboard in the case of compression resistance

- Hexagonal prism is show as an optimal solution due to better compression resistance and larger volume for the same amount of material, with minimal losses of space in collective transportation.

This research is limited to the samples tested in the paper and should be expanded in further research. Multiple variables should be additionally tested separately (size of paperboard sheets, size and heights of shapes, other types of paperboard grades and grammages). Those results should also be compared with results of packaging shapes with different types of closing components (flaps, crash lock, glued locks... etc.)

\section{REFERENCES}

[1] Al-Turaif, H.: "Surface coating properties of different shape and size pigment blends" Progress in Organic Coatings, 65 (3), 322-327, 2009. doi: 10.1016/j.porgcoat.2009.01.001.

[2] Becker, L., van Rompay, T.J.L., Schifferstein, H.N.J., Galetzka, M.: "Tough package, strong taste: The influence of packaging design on taste impressions and product evaluations", Food Quality and Preferences, 22 (1), 17-23, 2011. doi: 10.1016/j.foodqual.2010.06.007

[3] Guo, Y., Hou, J., Xu, W., Cao, G.: "Comparison Studies on Strength Properties of Corrugated and Honeycomb Composite Paperboards". Proceedings of 17Th IAPRI World Conference on Packaging (International Association of Packaging Research Institutes: Tianjin, China, 2010)

[4] Hales, T.C.: "The honeycomb conjecture", Discrete \& Computational Geometry, 25 (1), 1-22, 1999.

[5] Hoffmann, J.: "Compression and cushioning characteristics of moulded pulp packaging", Packaging Technology and Science, 13 (5), 211-220, 2000. doi: 10.1002/1099-1522(200009)13:5<211::AID-PTS515>3.0.CO;2-0

[6] Coles, R., Kirwan, M. eds.: "Paper and Paperboard Packaging, in: Food and Beverage Packaging Technology", (Oxford, Wiley-Blackwell, 2011), page 213. doi: 10.1002/9781444392180.ch8

[7] Lu, C., Qi, M., Islam, S., Chen, P., Gao, S., Xu, Y., Yang, X.: "Mechanical performance of 3D-printing plastic honeycomb sandwich structure", International Journal of Precision Engineering and Manufacturing-Green Technology, 5 (1), 47-54, 2018. doi: 0.1007/s40684-018-0005-x

[8] Pantin-Sohier, G.: "The Influence of the Product Package on Functional and Symbolic Associations of Brand Image", Recherche et Applications en Marketing (English Edition), 24 (2), 53-71, 2009. doi: 10.1177/205157070902400203

[9] Raghubir, P., Greenleaf, E.A.: "Ratios in Proportion: What Should the Shape of the Package Be?" Journal of Marketing, 70 (2), 95-107, 2006. doi: 10.1509/jmkg.70.2.95

[10] Räz, T.: "The silent hexagon: explaining comb structures", Synthese, 194 (5), 1703-1724, 2016. doi: 10.1007/s11229-016-1014-3

[11] Silayoi, P., Speece, M.: "Packaging and purchase decisions: An exploratory study on the impact of involvement level and time pressure", British Food Journal, 106 (8), 607-628, 2004. doi: 10.1108/00070700410553602

[12] Vable, M.: "Mechanical Properties of Materials", 2nd ed, URL http://madhuvable.org/wpcontent/uploads/2016/04/Entire\%20Book\%202018.pdf (last request: 2018-10-17) 
[13] Wang, D.M., Wang, Z.W., Liao, Q.H.: "Energy absorption diagrams of paper honeycomb sandwich structures", Packaging Technology and Science, 22 (2), 63-67, 2009. doi: 10.1002/pts.818

[14] Wang, D.: "Impact behavior and energy absorption of paper honeycomb sandwich panels", International Journal of Impact Engineering, 36 (1), 110-114, 2009. doi: 10.1016/j.ijimpeng.2008.03.002

[15] Wistara, N., Young, R.A.: "Properties and treatments of pulps from recycled paper. Part I. Physical and chemical properties of pulps", Cellulose, 6 (4), 291-324, 1999.

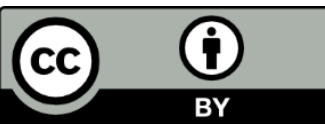

(C) 2018 Authors. Published by the University of Novi Sad, Faculty of Technical Sciences, Department of Graphic Engineering and Design. This article is an open access article distributed under the terms and conditions of the Creative Commons Attribution license 3.0 Serbia

(http://creativecommons.org/licenses/by/3.0/rs/). 